Lanas et al (2017) Engaging with theoretical diffraction in teacher education

Maija Lanas, Pauliina Rautio, Anne Koskela, Susanna Kinnunen, Elina Viljamaa \& Jaana Juutinen (2017) Engaging with theoretical diffraction in teacher education, Discourse: Studies in the Cultural Politics of Education, 38:4, 530-541, DOI: 10.1080/01596306.2015.1126917

\title{
Engaging with theoretical diffraction in teacher education
}

\begin{abstract}
This article presents a study in which we began with a question "how to teach theoretical reflectivity in teacher education, and ended with a sentence "there is theoretical diffraction in teacher education". The research presented in this paper took place in the context of a university course in which we have been involved for the past two years. During the course we simultaneously pursued to teach theoretical reflection and to analyse what was happening as we taught theoretical reflection. For two years we asked, 'What are students doing while we are trying to engage them in theoretical reflection?' We noted that students are engaged in theory, but not in ways easily readable to the educators, and that the process could rather be called theoretical diffraction than reflection. Theoretical diffraction during the course was patterned by existing discursive practices: 1) disciplining emotions and focusing on control and answers, 2) personalising school as the teacher and personally defending it, 3) prioritising practice over theory and seeing both as dogma.
\end{abstract}

KEYWORDS: teacher education, poststructuralism, theory, reflection, subjectivation, diffraction 
Lanas et al (2017) Engaging with theoretical diffraction in teacher education

\section{Engaging with theoretical diffraction in teacher education}

\section{Introduction}

The difficulty of introducing theoretical reflection into teacher education has often been attributed to student resistance to theory. The mismatch between what is taught and what is taken up is blamed on the students rather than on how the pedagogical practice itself is planned and performed (Taguchi, 2005, 248) or on the ways in which teacher education is structured. According to Barcan $(2002,352)$, the trope of student resistance all too often masks our own resistance to thinking more about why some students don't want to hear what we have to say. It is too often an easy professional option that protects us from having to think about and develop strategies around the impact of theory on the lives of those who we teach (Barcan 2003, 351). In this paper we address the challenge of teaching theoretical reflectivity in teacher education. We will do this by describing a course in which we have been involved for the past two years, in which we simultaneously pursued to teach theoretical reflection and to analyse what was happening as we taught theoretical reflection. Our research problem ended up partly undoing itself: The issue was not "how can we to teach theoretical reflection to students", but rather "there is theoretical diffraction".

"Diffraction is an optical metaphor for the effort to make a difference in the world....

Diffraction patterns record the history of interaction, interference, reinforcement, difference. Diffraction is about heterogeneous history, not about originals. Unlike reflections, diffractions do not place the same elsewhere, in more or less distorted form." (Donna Haraway in Barad 2007, 72)

Karen Barad goes on to argue that while "the methodology of reflexivity mirrors the geometrical options of reflection, and [...] remains caught up in geometries of sameness", diffractions are, by contrast, "attuned to differences - differences that our knowledge-making practices make and the effects they have on the world" (Barad 2007, 72).

Diffraction is a concept not commonly used when discussing interaction between an educator and a student. It is more often introduced as an alternative methodology to for example critical reflection (taken up in educational research by for example Davies 2014, Lenz-Taguchi \& Palmer 
Lanas et al (2017) Engaging with theoretical diffraction in teacher education

2013, Mazzei 2014, Seghal 2014, Taylor \& Blaise 2014, Prophet \& Pritchard 2015). Whereas reflection and reflexivity might document categories of difference, diffraction is itself the process whereby a difference is made and made to matter (Davies 2014, p.734). As a methodology, it "can be understood as an enactment of flows of differences, where differences get made in the process of reading data into each other, and identifying what diffractive patterns emerge in these readings (Lenz-Taguchi \& Palmer 2013, p.676). According to Lenz-Taguchi and Palmer (ibid.), researchers applying a "diffractive style of reading" can identify the intra-activities that emerge in the intersection of data, theory, methodology and researcher. Here, the relation between knower and known can no longer be described as one of distant gaze, but to engage in a process of knowing is to be part of the equation, to be entangled in intra-action (Seghal 2014, 189). In this way, diffraction is not a singular event that happens in space and time; rather, it is a dynamism that is integral to spacetimemattering (Barad 2014 p. 169). In this article, we suggest that this applies also to engaging with theory in teacher education.

We will begin the paper by introducing the demand for teaching and practicing theoretical reflection in teacher education - the base on which the research was built - and by describing how we pursued to interrogate our own 'response-ability' as well as 'response-readyness' (Taguchi 2005,248 ), and to produce a 'transitional space' (see also Philips 2010) to cultivate different ways of understanding and imagining in teacher education, to find ways to make space for readings and 'ways of understanding and doing that have been excluded or become invisible, or impossible to even think in the shadow of normative truth-claims' (Taguchi 2007, 286). To begin with, we had no idea what this could look like - what do ways that are impossible to think about look like? - And how do we ago about trying to thinking about them? This article presents our attempt to do so.

After setting the scene, we will describe our efforts in making sense of the participants of the process in which we teach theory to students. There were six teacher educator-researchers taking part in the course, and roughly 140 students in both years. In an attempt to not be caught on 'voice' (e.g. st. Pierre 2008) or students as autonomous subjects in need of recognizing, we formed a plural teacher educator-subject (consisting of the six of us) and a plural teacher student-subject (consisting of a total of over 200 students). The plural subjects allowed us to interrogate what happens when we, as a group of educators, attempt to teach theoretical reflection to a group of students. 
Lanas et al (2017) Engaging with theoretical diffraction in teacher education

\section{The demand for teaching and practicing theoretical reflection in teacher education}

Multiple authors underline the importance of theoretical reflection in teacher education. It is seen as something we should both teach and do. Firstly, the argument for teaching theoretical reflection is well-founded on the fact that unless students have the means to understand the contradictions and tensions between discourses, they are most likely subjectivated by those discourses most resembling what they already know (Green \& Reid, 2008, 20, 26). Students have, for example, gone through many years of schooling in which they were mostly passive, where knowledge was considered to be held by the teacher and in readings and students are expected to access, decipher and then return that knowledge to the teacher. While students might not have liked this kind of learning, it has become a habit and they have been subjectivated by it (Britzman, 2003; Segall, 2008). As Taguchi (2007) suggests, students do not come to their education with an empty toolbox needing to be filled with educational theories and methods, but rather with a toolbox that is already filled (and continuously refilling itself), with tools needing to be unpacked, investigated and reformulated. This process of working on the toolbox is what theoretical reflection is about. Until such reflection takes place, normalising discourses are likely to dominate the perceptual awareness of student teachers, which has implications on what they might learn, what they might become and what they might expect of others (Sumara, D., Davis, B. \& Iftody, T., $2008,170)$. Teacher education not only reflects larger social values but also infuses the social with particular values, thus shaping the societies which we live in (Phelan, 2011, 214). 'Not only do people produce theory, but theory produces people ... different theories of the subject make possible different lives' (St. Pierre 2001, 142), and through theoretical reflection, student teachers may learn to understand how they ' $d o^{\prime}$ ' children, gender, race, ethnicity, disabilities, success and failure, as well as making themselves as teachers, while performing pedagogical practice and teaching 'innocent' contents of learning, that are already constitutive of the world and power production within that world (Taguchi 2007, 286).

At its worst, theory is taught as a catechism, a set of repeatable moral precepts, a mode of preventing thought; and at best, theory is offered as the provoker of questions, the opener of minds, and provides nuanced and insightful ways of understanding the world (Barcan 2003, 351352). Barcan (2003) notes that how we teach theory links directly to what we expect students to do with theory in their future occupation as teachers. We implicitly offer our students a potential 
Lanas et al (2017) Engaging with theoretical diffraction in teacher education

subject position to occupy (Barcan 2003, 349-350). At best, theory is seen as a means for thinking in, with and about one's practice as a teacher. For such theorising to take place, students need to be asked to implicate their own teaching with theory, to examine the theories they already hold about education, teaching and learning, and to re-theorise their teaching and their practicum environments (Klein, 2012; Segall, 2008; Taguchi, 2007). Theoretical reflection comprises learning to understand the processes through which students are made subject, so that they 'are better positioned to resist particular forms of subjectivity, and thereby actively choose to think and do things differently' (Davies \& Banks, 1995, 46), and involves a continuous process of unpacking and repacking one's own thinking and relating existing theories to other ways of thinking (Taguchi 2007, see also Green and Reid (2008), (Phillips, 2010). Instead of engaging in reflection, students may just learn to present reflection (Atkinson, 2012).

Secondly, the argument for doing theoretical reflection is founded on the fact that teacher education is a 'knowledge-producing community' which applies its standards of credibility and epistemic values to theory choice and exercises 'epistemological gatekeeping' (Kinsella \& Whiteford, 2009). In effect, any knowledge-producing community defines rules of exclusion, sets boundaries and imposes closures, which limit what counts as legitimate, valid knowledge, while operating in a manner that is largely implicit, taken-for-granted and unacknowledged. Knowledge generation and utilisation is thus a social practice that involves disciplining the community itself and its members, and the validation of knowledge is influenced by the standpoint of the existing community of experts, who apply their standards of credibility (Kinsella \& Whiteford, 2009, 251).

Thus, academic communities should engage with what Kinsella and Whiteford (2009) call epistemic reflexivity: critiquing and contributing to disciplinary knowledge and critically considering 'who' makes epistemological choices in the profession, and the consequent implications for the theories we adopt. Defining reflexivity as the 'act of interrogating interpretive systems', Kinsella and Whiteford demand going beyond pragmatic reflection to carefully interrogate the very conditions under which knowledge claims are accepted and constructed, recognising the sociality of the process of knowledge generation and the social conditions under which disciplinary knowledge comes into being and gains credence. In the context of epistemic gatekeeping and uninvestigated discourses, what is new 'may appear enigmatic, anomalous, absurd, or even dangerous" (Phelan 2006, 165). It may point to a strangeness at the core of the 
Lanas et al (2017) Engaging with theoretical diffraction in teacher education

profession; in doing so, it may be received as displacing and unleashing danger for someone (Phelan 2006, 165; Barcan 2003, 353).

\section{Teaching reflection}

This research was carried out in the form of a yearly recurring course organised and led by the authors of this paper. Informed by the accounts cited above, we pursued to teach theoretical reflexivity: saw and introduced theory as the provoker of questions; the opener of minds; as something that produces people and enables different lives; as a means for thinking in, with, and about one's practice; and for reflecting the contradictions and tensions between discourses in order to transform those structural aspects that hinder the accomplishment of educational goals.

We planned our teaching with awareness of the three challenges for teaching theoretical reflection, ingrained in the knowledge production processes in teacher education, listed by Segall (2008). The first challenge, called reading without writing, refers to a process in which student teachers don't tend to think of themselves as theorists or theoretical reflectors but as practitioners who are merely required to implement theories generated by others (Segall 2008, 17). The second challenge, which Segall calls ignorance, speaks of the active dynamic of negation, an active refusal 'to acknowledge one's own implication in the information' (Segall 2008, 18) and breaking the theory - deeming it as 'not working' - before it has a chance to break the learner (Britzman 2003, 86). Student teachers are not simply performing an external academic exercise, but their understandings of teaching, learning, teachers, society and children are at stake. Segall suggests that breaking habits is especially difficult for those students who were successful in the existing system, who are inclined to see critical reflection on teaching and learning, particularly on their own teaching and learning, more as a burden than for the freedoms it allows. That is because, in their eyes, student teaching is a time to primarily gain confidence in teaching, not a time in which one's existing confidence about teaching gets troubled (Segall 2008, 24).

The third challenge identified by Segall, reflection as an individual rather than a collective process, links to teacher education's traditional roots in the humanist understanding of the individual as autonomous and rational. According to Klein (2012), this kind of humanist discourse is problematic because it looks to the individual, rather than to the working of extant discourses, for the answer to educational problems. Typical but insufficient reflection, then, not only positions teachers to 
Lanas et al (2017) Engaging with theoretical diffraction in teacher education

'see their problems as their own, unrelated to those of other teachers', but also diminishes the possibility of any consideration of the social conditions of schooling and their implication in broader political, social and economic discourses that influence the teacher's work within the classroom (Segall 2008, 20; see also Zeichner 1996, 205).

We wanted students to view themselves as generators of theory, not consumers of it; to interrogate the conditions under which knowledge claims are accepted and constructed, recognising the sociality of the process of knowledge generation and critically considering 'who' makes epistemological choices; to examine and to re-theorise the theories that they already hold, understanding the processes through which they are made subject; and to acknowledge the ways in which we 'do' children, parents, gender, etc. through various theoretical choices. For the content of the course, we drew on post-structural theories of childhood. Such theories point out, as Britzman efficiently states, that we 'still manage to approach development as if it is a correction for childhood" (Britzman 2003, 1). The course thus challenged some of the traditional ideas in education - which have also saturated these students' disciplinary education for the three years or so prior to this course.

The course has been given twice now, consisting of a series of lectures, an assignment, and ending with workshop sessions. The teaching work on the course was divided: Some of us gave lectures, some of us lead practice seminars alone or in pairs (the students were divided in five groups for practice seminars), and others did both. In order to 'see the invisible', we continually wrote down our observations, thoughts, perceptions and experiences as course leaders. When the course was ongoing, we met once a week to discuss our notes. As an example, we repeatedly caught ourselves worrying that students had not learned 'correctly' and that they did not reflect in the 'right' way - thus continually contradicting our own stance.

We planned the second year course assignment with the hope that it would require thinking about the theory we have introduced, but would not seek to 'measure' this thinking in terms of expected learning outcomes. Also, the assignment could not be one in which students could utilise their skills to present reflection (Atkinson 2012), or one in which they would start looking for the 'right' answer. The agreed task was 'What does the statement "The up-bringer ${ }^{1}$ makes the child" mean,

\footnotetext{
${ }^{1}$ The assignment does not translate perfectly into English. In Finnish, there is a commonly used word 'kasvattaja', the direct translation is 'grower' or 'up-bringer'. In additions, the word 'tehdä' translates into both 'make' and 'do'.
} 
Lanas et al (2017) Engaging with theoretical diffraction in teacher education

and what does it not mean? Reflect on the argument based on the theories presented during the lectures.' The course assignment was given to the students during the first lecture, so they could work on the theory with the question throughout the lectures. The students could do the assignment in pairs, and they handed in a total of 109 essays, each between two and six pages long. Most essays comprised some of the theories discussed during the lectures, built around references to personal histories, to the practice of education, and justifying the students' own ideas of school.

The workshops led by the authors of this paper began after the lectures and the essay assignment, and they consisted of eight meetings and lasted for one month. Each group had about 15-20 students and had the same goals but different tasks, including the writing of learning journals and compiling mini research designs. For example, in one group the students carried an unboiled egg with them for a week in order to try and interrupt their thinking and 'default settings' in their everyday practices. In another group the students re-read their own bachelor's theses in order to analyse the construction of a child in their own work.

\section{Constructing the response of the plural students-subject}

If educational engagement is not perceived as a normative on/off switch (in which students are seen as either successfully presenting engagement or failing to present engagement in ways that are easily understandable to teachers), but students are seen essentially engaged in their own learning, and if we try and let go of our own on/off perceptions, what happens when we attempt to teach theoretical reflection to a group of students? We thought about (analysed) the two kinds of student responses we saw during the course: 1) the assignment responses (in which students tried to present learning in the ways in which they have learned how it should be presented), and 2) spontaneous responses we experienced as challenging, especially during the practice workshops, such as fleeting comments, spontaneous reactions, initiations for discussions and periods of silence. In our regular meetings we repeatedly asked: 1) What took place in the essays beyond presenting learning? 2) What do the 'challenging' responses ask from us?

For analytical purposes, we have identified an underlying plural subject, 'students', which we have focused on as one subject. By doing so, we do not intend to make generalisable statements about 
Lanas et al (2017) Engaging with theoretical diffraction in teacher education

students, nor do we intend to construct stereotypes about student teachers. Instead, the plural student-subject is as ambivalent and plural as any other subject: the outlines are temporary cuts. The subject has multiple voices, histories, frameworks, directions, origins, goals and so forth. And although the students-subject is one affective complexity, it does not refer to a sense of 'us'. As an analytical tool the students-subject helps us think about what takes place as we, as teachereducators, face 140 students with a goal to help them become theoretically reflexive. Thus, when we speak of the students-subject, we speak of the subject for whom we prepare our lectures, the subject whose responses we try to anticipate. The students-subject is a living body, the affective responses of each part linking to and inviting the responses of another part. When conducting a course for 140 students, we try and speak with the body, the 'living thing' of students. So, when we write about the students-subject, we refer to the 'living thing' of 140 students who come into being in the relation of working theory with the six of us - and in the same relation we come into being as teacher-educators.

\section{What happened beyond presenting learning?}

Firstly, in order to analyse what took place in the essay-assignments, we constructed the essay response of the student-subject through a joint task. We divided the 109 essays between us, and highlighted in each essay the responses to the assignment question, 'What does the statement "The up-bringer makes the child" mean?' The highlighted responses were placed in a separate file that was eventually 26 pages long. We thus produced one single response of one student-subject, as it were. This was a response that no individual student wrote but one that we, together, read. The student-subject's response was internally conflicting and repetitive (just like most of the individual student essays were). Next, we began making sense of this fragmentary response by placing all repetitions together, and by differentiating between conflicting arguments. Finally, we had a less fragmentary and repetitive but equally internally conflicting essay response by the students-subject. We decided to view the essay response as a text produced by a subject engaged in a discussion, the content and participants of which we do not know. What discussion is the subject taking part in? What is the subject saying?

After repetitive reading of the essay of the student-subject we noted that it portrayed a debate over what education (up-bringing) is. In this way, students were engaged in theoretical discussion at the heart of education and we, as the readers of the assignments, were invited in this 
Lanas et al (2017) Engaging with theoretical diffraction in teacher education

theoretical discussion. Until this point, we had seen ourselves as the ones engaging students in a theoretical discussion about childhood, and now we began to see the tables turned: students engaging us in a discussion about education. This was not an alternative discussion to the one we were pursuing, but another aspect to the same one: in order to discuss what childhood may mean, students had to also rethink what education may be. There were roughly four different takes on education which the student-subject was discussing, described here from the most popular one onwards:

1. Education is adult influence over the child: adults are responsible for influencing children/ adults influence children unintentionally/ there are a troubling effects to adults' power to influence children/adults' opportunities to influence children are limited/ the idea of education as one-way influence as ethically troubling.

2. Education is responding to needs: The educator knows the needs of each child and knows how to respond to them.

3. Education is a relationship between humans: based on the personality of the child/ based on the educators personality the personality/ between two humans growing together/ the adults' responsibility is based on obligation

4. Education, environment and childhood are phenomena that produce each other: education is something done by the entire social-cultural-material environment children themselves included, and thus makes children of certain kind / education influences the entire socialcultural-material environment and society/ childhood is socially-culturally-materially produced as a certain kind.

This is when the concept of reflection, and the image of a mirror it carried, began to fall short as a tool for us for thinking about what was happening. The result of the teaching process - the "learning outcome" - the theories the students had ended up with, presented themselves not as an image or reflection, but as a "resultant wave [which] is a sum of the effects of each individual component wave (Barad 2007, 76).

\section{What do the challenging responses say?}

Secondly, during the two years, we wrote down the challenging responses we noted - the fleeting comments, the spontaneous reactions, the silences and the initiations during the discussions in the course. Our notes included responses that did not make sense to us, frustrated us, or challenged us in other ways - and which we were at times tempted to brush off as student failure to present learning. We brought these to each other, trying to make sense of them and our responses to them. At times we were in on/off-mode, too frustrated with our efforts to engage the students in our theoretical discussions to see what they were engaging us in. We discussed 
Lanas et al (2017) Engaging with theoretical diffraction in teacher education

this in our meetings throughout the semester, continually forcing our discussion away from on/off thinking, towards asking: what else is taking place? What else are the responses saying? Thus, we purposefully directed our gaze away from our instinctive focus on what is lacking in the challenging responses towards what is present in the responses: What were the other discussions in which the students-subject was engaged in, which challenged the discussion in which we tried to engage them? We decided to think about the student responses as the responses of one subject taking part in a discussion the rest of which we cannot hear: what is the discussion about? We could identify three 'clusters' of topics:

\section{1) Disciplining emotions and focusing on control and answers}

The students-subject was engaged in a discussion about rules regarding emotions of teachers, as well as in a discussion about the traditional image of a teacher as the knower, as the one in control. For example, the students-subject commonly expressed excitedness and eagerness and on the other hand debated whether it is OK to feel insecurity and uncertainty as a future teacher. The student-subject often approached topics in terms of teacher control and in polarised ways: either the teacher has all of the control or none of it. For example, discussing the possibility that students have power in class was at times seen as depriving teachers of control in class. That teachers should have all of the control in class was justified as being for the good of the children: 'The teacher has to be in control so that the environment is safe for the students'. In this way, the student-subject took part in the broader ethos of teacher control and emotion management, and utilised a shared value in the field, 'the best for children', in maintaining this ethos.

\section{2) Personalising school into the teacher and personally defending it}

The students-subject took part in the broader societal ethos of Finnish school as a saving grace, and in which the school is personalised in the (excellence of) Finnish teachers. Pre-service teachers have internalised the idea of the reflective practitioner, who takes on the educational challenges by constantly developing one's own self. However, they have also internalised how to simultaneously look away from the discourses within which they develop their teacher selves. Thereby, when these structures and norms that are invisible to the student-subject are questioned, the subject takes the critique personally. For example, the students-subject defended school whenever it was perceived to be in any danger of being questioned: if a teacher educator asked whether and how various students can be heard in school, the subject replied as if the educator had argued that students are not heard in school. Moreover, the students-subject 
Lanas et al (2017) Engaging with theoretical diffraction in teacher education

replied as if it had been argued that it is the teacher who does not listen to children. In general, the subject often replied to questions about practice as if they were questions about the teacher, and particularly about him/herself as a future teacher. For example, when it was asked if assessment of behaviour is a practice that is linked to power, the subject replied 'I believe in Finnish teachers' and pursued to discuss how much effort teachers invest in assessment.

\section{3) Prioritising practice over theory and seeing both as dogma.}

The students-subject took part in broader instrumentalist and school-centred educational discourse in which the relevance of theories is judged in terms of direct connectedness to school. Instead of seeing theorising as something enabled by teacher education, or as a skill that should be trained, the subject came up with real and imagined factors that would prevent doing theory in practice - not criticising the theory, but deeming it irrelevant or inapplicable.

For example, the subject was often rigorously focused on school, and the question 'what does this have to do with school' was commonly asked - and answered - by the students-subject. In the extreme, the perspective of the student-subject was that 'if it does not have anything to do with school, I do not have to know it.' At the same time, this focus limited the discussion: whenever the student-subject was not thinking of theory in terms of school practice, the discussion was multiple and theoretically rigorous, but if the student-subject located thinking in the school context, the discussion became repetitive of old norms, prioritised the school context over theory and deemed theory as unfitting or irrelevant. The student-subject 'already knew' the practice, and applied theory to what it already knew, failing to recognise what was left outside its practical knowledge base. The student-subject tended to take a stand against questions without answers, arguing that teacher education is meant to provide answers and solutions. Theory was seen equally dogmatically. For example, as one student handed in the course work she stated: 'I'm afraid this essay falls short of the expectations regarding theory.' The essay was full of theorising that makes sense and was informed and coherent - but it did not focus on explicitly presenting knowledge of existing theories by depicting or quoting them.

\section{Theory becoming diffracted}

The research suggests that teaching theoretical reflection is not an on/off -question of whether students become engaged in theoretical discussions or not, but that while student teachers are 
Lanas et al (2017) Engaging with theoretical diffraction in teacher education

engaged in theoretical discussions at the core of the discipline, such discussion is patterned by existing discourses. Whereas the image of theoretical reflection invites an image of mirroring and sameness, diffraction invites an image of theory passing through obstructions, so that it becomes spread differently than it would be without the obstructions. Thus, by replacing the notion of reflection with the notion of diffraction, the clusters could be made sense of in a new way, as interference patterns created by waves interfering with each other (Barad 2007, 77). It is not that we reflect theory with students, but that theory becomes diffracted as it passes and twirls around the various clusters which exist in the space in which the theory is moving. To begin with, we wanted students to reflect, to view themselves as generators of theory, to critically consider 'who' makes epistemological choices; to examine and to re-theorise the theories that they already hold, understand the processes through which they are made subject and in which they make subjects of others. Now we see such a goal set by us as one more cluster in which the theories twirl.

Davies $(2014,734)$ writes - and we add in square brackets:

A diffractive approach opens an onto-epistemological space of encounter where a researcher's [educator's] task is not to tell of something that exists independent of the encounter (producing the appearance of truth), but to open up an immanent subjective truth-that which becomes true, ontologically and epistemologically, in the moment of the encounter. An encounter in this sense is experimental-the researcher [educator] does not know in advance what onto-epistemological knowledge will emerge from the experimental mix of concepts, emotions, bodies, images, and affects. Diffraction, as a concept for thinking about analytic [educative] processes, does not try to fix the analytic [educative] process so that it can be turned into a methodic set of steps to be followed. Rather, it opens the possibility of seeing how something different comes to matter, not only in the world that we observe but also in our research [educative] practice. Diffractive research [education] practices "make evident the entangled structure of the changing and contingent ontology of the world, including the ontology of knowing. In fact, diffraction not only brings the reality of entanglements to light, it is itself an entangled phenomenon" (Barad, 2007, p. 73).

We suggest that the common cause of frustration among teacher-educators, the one of students being uninterested in theory, does not in fact reflect student disinterest, but our own insufficient means of recognising the diffracted theory as theory. We argue that many such frustrated accounts in fact arise from the dogmatic perception of theoretical reflection as one in which 
Lanas et al (2017) Engaging with theoretical diffraction in teacher education

students present, reflecting on what they are told to reflect. This entails the implicit assumption that discursive practices are something we could "undo", or discharge by reflecting them. We suggest that they are, instead, clusters which pattern the diffraction of theory, and when doing so, point to various discursive conditions for engaging with theory.

Student teachers are subjectivating and becoming members of the existing community of experts, within the national 'school' discourse, and their utterances have to make sense in the discourse in order to be understandable. Finally, we suggest that during pre-service teacher education, in students' eyes, the 'community of existing experts' does not consist of academics, but the practising teachers in the field, since 'the field' is their goal. Such a constitution of 'practising teacher' is not any actual teacher, but a faceless construction, put together based on their previous experiences, the media, their peers, etc., and most of all by themselves as they subjectivate as a member in the community of 'practising teachers'. The power of such a construction in Finnish context most likely derives from the professional autonomy and respect Finnish teachers enjoy nationally and internationally ${ }^{2}$. In this way, it is the students' idea of a practising teacher which represents 'the community of existing experts' and controls the epistemological borders of the field - an idea partly produced by them as they engage in the epistemic practices, such as the three clusters identified in this research.

The research has been funded by the Academy of Finland, project number 267166

\section{References}

Atkinson, B. (2012). Strategic compliance, silence, "Faking it," and confession in teacher reflection. Journal of Curriculum Theorizing, 28(1), 74-87.

\footnotetext{
${ }^{2}$ Finnish teachers are not controlled in any way (no inspectorates, no officially approved material, no detailed national curriculum, no standardised tests), but they are considered to be professional, autonomous experts.
} 
Lanas et al (2017) Engaging with theoretical diffraction in teacher education

Barcan, R. (2002). Problems without solutions: Teaching theory and the politics of hope. Continuum: Journal of Media \& Cultural Studies, 16(3), 343-356. doi:10.1080/1030431022000018708

Britzman, D. P. (2003). After-education : Anna freud, melanie klein, and psychoanalytic histories of learning. Albany: State University of New York Press.

Davies, B. (2014). Reading Anger in Early Childhood Intra-Actions: A Diffractive Analysis. Qualitative Inquiry, 20(6), 734-741. doi:10.1177/1077800414530256

Green, B., \& Reid, J. (2008). Method(s) in our madness, poststructuralism, pedagogy and teacher education. In A. M. Phelan, \& J. Sumsion (Eds.), Critical readings in teacher education : Provoking absences (pp. 17-31). Rotterdam: Sense Publishers.

Kinsella, E. A., \& Whiteford, G. E. (2009). Knowledge generation and utilisation in occupational therapy: Towards epistemic reflexivity. Australian Occupational Therapy Journal, 56(4), 249258. doi:10.1111/j.1440-1630.2007.00726.x

Klein, M. (2012). How inconvenient assumptions affect preservice teachers' uptake of new interactional patterns in mathematics: Analysis and aspiration through a bifocal lens. Educational Studies in Mathematics, 80(1), 25-40. doi:10.1007/s10649-012-9390-1

Mazzei, L. A. (2014). Beyond an Easy Sense: A Diffractive Analysis. Qualitative Inquiry, 20(6), 742746. doi:10.1177/1077800414530257

Phelan, A. M. (2011). Towards a complicated conversation: Teacher education and the curriculum turn. Pedagogy, Culture \& Society, 19(2), 207-220. doi:10.1080/14681366.2011.582257 
Lanas et al (2017) Engaging with theoretical diffraction in teacher education

Phillips, D. K. (2010). On transitional space, unresolved conflicts, and an uncertain teacher education. Teachers \& Teaching, 16(5), 633-644. doi:10.1080/13540602.2010.507970

Prophet, J., \& Pritchard, H. (2015). Performative Apparatus and Diffractive Practices: An Account of Artificial Life Art. Artificial Life, 21(3), 332-343. doi:10.1162/ARTL_a_00174

Segall, A. (2008). Why teaching critical social theory as theory might not be enough. In R. J. Helfenbein, \& J. Diem (Eds.), Unsettling beliefs : Teaching theory to teachers (pp. 15-29). Charlotte, NC: Information Age Publishing.

Sehgal, M. (2014.) Diffractive Propositions: Reading Alfred North Whitehead with Donna Haraway and Karen Barad, Parallax, 20:3, 188-201, DOI: 10.1080/13534645.2014.927625

Sumara, D., Davis, B. \& Iftody, T. (2008). 101 ways to say “Normal”. In A. M. Phelan, \& J. Sumsion (Eds.), (pp. 155-172). Rotterdam: Sense Publishers.

Taguchi, H. L. (2005). Getting personal: How early childhood teacher education troubles students' and teacher educators' identities regarding subjectivity and feminism. Contemporary Issues in Early Childhood, 6(3), 244-255.

Taguchi, H. L. (2007). Deconstructing and transgressing the Theory-Practice dichotomy in early childhood education. Educational Philosophy \& Theory, 39(3), 275-290. doi:10.1111/j.1469$5812.2007 .00324 . x$

Lenz Taguchi, H., \& Palmer, A. (2013). A more 'livable' school? A diffractive analysis of the performative enactments of girls' ill-/well-being with(in) school environments. Gender \& Education, 25(6), 671-687. doi:10.1080/09540253.2013.829909 
Lanas et al (2017) Engaging with theoretical diffraction in teacher education

Taylor, A., \& Blaise, M. (2014). Queer worlding childhood. Discourse: Studies In The Cultural Politics Of Education, 35(3), 377-392. doi:10.1080/01596306.2014.888842 